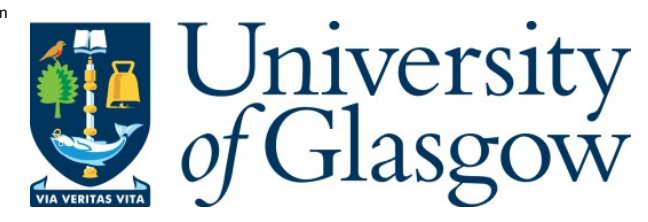

A skins, K. (2008) (Re)negotiations: towards a transformative geopolitics of fear and otherness. In: Pain, R. and Smith, S. J. (eds.) Fear: Critical Geopolitics and Everyday Life. Series: Re-materialising cultural geography . A shgate, A Idershot, pp. 235-248. ISB N 9780754649663

Copyright (c) 2008 A shgate

A copy can be downloaded for personal non-commercial research or study, without prior permission or charge

Content must not be changed in any way or reproduced in any format or medium without the formal permission of the copyright holder(s)

http://eprints.gla.ac.uk/99182/

Deposited on: 10 N ovember 2014

Enlighten - Research publications by members of the U niversity of Glasgow http://eprints.gla.ac.uk 
(re)negotiations: towards a transformative geopolitics of fear and otherness

\section{Kye Askins}

"While I do want to underscore that I do embrace colour-blindness as a legitimate hope for the future, I worry that we tend to enshrine the notion with a kind of utopianism whose naivety will assure its elusiveness."

(Williams, 1997:2)

"and while no one can argue that black self-help is not a fine thing, I wonder about its meaning when it is used as an injunction that black concerns be severed from the ethical question of how we as a society operate."

(Williams, 1997:66)

Let me start with some explanation, the story behind this chapter, if you will. I am drawing here on the theoretical and empirical work undertaken for my PhD thesis, which explored perceptions and use of the English national parks amongst people from Asian and African Caribbean backgrounds. As such, my narrative is situated: the empirical research was undertaken in the cities of Sheffield and Middlesbrough (in the north of England), and the Peak District and North York Moors national parks, between 2001 and 2004. (And I am indebted to the hundreds of individuals who gave me their time and shared their experiences and thoughts.) However, the issues discussed here may be useful more widely when considering the geopolitics of fear in everyday lives. I should also explain that, as part of the funding of the research, I was required to write policy recommendations for the national park authorities. I want to speak to both theoretical and policy concerns because I believe there is an ethical duty to address research to intervention - very carefully. Specific policy is not detailed here ${ }^{1}$, rather I touch on an overarching ideology for policy direction.

And let me be upfront - my focus is on exploring how negotiating between and across bodily and spatial difference can move us towards a transformative politics of place and identity. I am arguing that we need honest engagements with the complex ways in which otherness and fear play out in the everyday - alongside an understanding that encounters between different groups draw upon, reiterate but also have the potential to shift how we see and how we feel about our others. I want to emphasise that these encounters occur in place, and are embedded in histories of

\footnotetext{
${ }^{1}$ The policy document that came out of the research is available at: http://www.visitnorthyorkshiremoors.co.uk/content.php?nID=675
} 
encounters re-produced through local, national and international discourses. But also that it is through a candid reckoning with fear, exclusion, and all those negative constructions that have very real material consequences, that we may move to a more radical openness offering possibilities for other emotions - empathy, care, even love - to become major players in our encounters with difference. However, I would warn that any 'pronouncements' are likely to be highly contested, fragile arrangements. That is, the content of this chapter surrounds the evolution of an inclusive, progressive version of visible communities in the English countryside (and England more broadly), and how we may encapsulate such fluid understandings of fear, identity and spatial in/exclusion within policy-making - while the tone is one of ongoing (re)visioning rather than a definitive account.

I also need to explain my use of the term 'visible communities' (after Alibhai-Brown, 2001) to describe people of Asian, African and Caribbean backgrounds. Terminology around ethnicity is highly problematic, and after a great deal of reflection during and since the research, I'm opting for this term to avoid both the homogenising tendencies of the term 'black' (as critiqued by Modood, 1992) and the power-laden term 'minority'. 'Visible communities' is not intended to reify visible difference from a white 'norm', but I use it as a political signifier to highlight that there are power inequalities endemic in English society, which are commonly grounded in perceptions of inferiority and threat attached to visible difference from a white 'norm' - especially in the English countryside.

And let me offer an overview. There is an important body of work around the social exclusion of visible communities and racism in the countryside (see Milburne, 1997; Cloke \& Little, 1997; Neal, 2002; Agyeman \& Neal, 2006), which in terms of fear/ anxiety tends to focus on the fear experienced by visible communities through both emotional and physical exclusion. However, I want to concentrate on the role of fear among white society in processes of social and spatial exclusion, and how we might progressively theorise and practically address this fear. Visible ethnic difference is recognised and reacted to, and non-white bodies continue to be marginalised as other in English society within everyday perceptions of difference caught up in global discourses around fear and 'terror' (as Hopkins and Smith, and Noble and Poynting show elsewhere in this volume). Given this, my narrative opens by examining debates regarding 'positive action', multiculturalism and equality, and how they remain trapped in/by the paradox of essentialising visible communities as always already and only different. Next, working through the construction of 'strangers' in 
dominant identifications of this other, I suggest that the concept of 'monsters' offers a more honest engagement with otherness. It first demands effacing the ambivalence accorded difference (awe as well as fear), and also offers a strategy for acknowledging, appreciating, holding on to the impossibility and possibility of sameness between self and other.

While most of my discussion surrounds issues regarding identity construction in place, the chapter moves on towards the end to focus on place and space itself. I argue that we need to understand the rural as positioned within a web of spaces, local, national and international, and call for a serious commitment to conceiving space relationally in order to shift exclusive constructions of ethnic difference and who can be where in contemporary England. Across the research, space as different and similar appeared interdependent within people's everyday geopolitics around fear and belonging: dualistic constructions of very fixed 'rural versus urban' rubbing alongside understandings of these spaces as porous, mobile and plural. I suggest that progressive theorising around multiculturalism/inter-ethnic encounters, which predominantly remains trapped in the 'only urban' realm, needs to critically engage with rurality; while thinking about the rural needs to engage with notions of multiethnic citizenship - that the rural sees itself and is thought through as a multicultural space.

\section{(re)viewing rural others}

positive action: multiculturalism, difference and equality

Throughout the research, visible community participants reiterated a desire to 'be together', to sustain mutual support and a sense of security, as well as emphasising that they should be encouraged and actively enabled to visit national parks. People described this need for positive action as necessary to redress imbalances endemic in English society, drawing on a discourse of 'strategic essentialism' (after Hall, 2000). Such calls for specific attention can be argued to stem from an 'affirmative politics of recognition' (Fraser, 1995), wherein visible communities challenge lived experiences of exclusion using the same fixed, essentialised identities through which they are marginalised. Rattansi (1999) links such 'affirmative politics' to an 'additive' model of representation central to the multiculturalism of liberal cultural pluralism pursued in England over the last two decades - a model based on minority-driven 
demand for 'recognition' and social advancement for racialised groups, with each 'minority' group 'added on' as/when it claims to be recognised.

Insert Figure 1 here: Affirmative politics of recognition

The intention of a 'politics of recognition' and positive action projects is to achieve equality of opportunity, through emphasising ethnic and cultural rights based on difference, and promoting the celebration of cultural pluralism. As Parekh (2000a:240) states:

"Equal rights do not mean identical rights, for individuals with different cultural backgrounds and needs might require different rights to enjoy equality in respect of whatever happens to be the content of their rights. Equality involves ... full recognition of legitimate and relevant [differences]."

The research engaged with positive action initiatives, in particular the work of the Black Environment Network (BEN) and a three year project jointly managed by BEN and the Council for National Parks called the Mosaic Project. Both Mosaic and BEN foreground the excluded status of people from 'ethnic' backgrounds ${ }^{2}$, campaigning for positive action to enable 'ethnic minority' participation in the mainstream environmental field, raising awareness of ethnic and cultural difference and highlighting the responsibilities of public bodies to be inclusive of diverse communities. Despite the positive aspects of this 'additive model' approach, however, within the research it seemed that countryside managers continued to see visible communities as rural others, as only different and fixed. Thus visible communities remained racialised. There is a need, then, to unsettle any 'celebration' of 'other' cultural practices that refuses the possibility of fluidity, pluralism or intercultural similarity - to avoid essentialising groups through emphasis on difference as spectacle. As Bennett (1998:4, original emphasis) writes:

\begin{abstract}
"state-managed multiculturalisms reify and exoticise alterity; addressing ethnic and racial difference as a question of 'identity' rather than of history and politics, they translate alterity as cultural diversity, treating difference (a relation) as an intrinsic property of 'cultures' and as a value (a socially 'enriching' one), to be presented as such."
\end{abstract}

\footnotetext{
${ }^{2}$ BEN "uses the word 'black' symbolically" and states that it works "with black, white and other ethnic communities" (BEN, 2003). In real terms, BEN predominantly engages with ethnic minority communities, who come from Asian, African Caribbean, Middle Eastern and Eastern European backgrounds.
} 
Exactly this kind of emphasis, albeit well-intended, was exemplified by an event held in the Peak District. Attended by national park staff, other relevant countryside management actors and visible community groups who had participated in the Mosaic Project, the day included lunch prepared by the visible community groups (each group contributed 'traditional' dishes to a buffet), followed by an afternoon devoted to 'ethnic minority activities': a tai chi workshop led by the Chinese group; henna tattooing by Indian women; Asian silk screen painting run by 'an Asian group'; a display of 'urban black street dancing' by 'urban black dancers', etc. While it was an enjoyable and 'successful' day, it was an invitation-only event (out of sight of visitors and residents), in which people performed to specific stereotypes. Undoubtedly, some intercultural exchange occurred between the visible community groups present, but for the national park staff/countryside managers it was a one-way 'see and learn' experience reiterating visible community difference.

This pluralist approach is applauded/demanded by many as part of the liberal multicultural agenda, as enthusiasm for African Caribbean carnivals, Asian Melas and the popularity of the Mosaic Project attest. Yet there has also been an increase in recent years of a 'politics of resentment' (Wells and Watson, 2005) among white (often but not only working class) groups to such 'affirmative politics of recognition', fuelling ethnic tensions in society. Bhattacharyya (1998:259) critiques the "feel-good multiculturalism" of cultural relativity as increasingly at odds with contemporary British society in which, given the widespread vilification of Muslims, pluralism seems a "concept out of time", and sees the possibility of a multiculturalism based on "getting by in cheerful diversity" decreasing. Thinking about events across the world since, her analysis rings even more acute. 'Cheerful diversity' in the everyday has arguably been replaced by a geopolitics of fear fuelled by a dominant western international discourse placing Muslims as feared and dangerous Others, which is then elided with people of Asian appearance, slipping further to (re)attach fear/danger to any/all nonwhite others (see Hopkins and Smith in this volume).

Indeed, political concern that cultural pluralism hasn't worked, especially apprehension surrounding the sense that society is increasingly segregated (eg. see Bunting, 2007) has led to a shift towards the ideology and rhetoric of 'community cohesion'. The cultural/ethnic other is no longer allowed free rein to be different - they may be different only as long as they adhere to a set of shared ideals and values (Cantle, 2001). These ideals and values, though, are non-negotiable and inevitably determined by dominant (white) society. From commitment to an 'English' sense of 
'fair play', to oaths of allegiance, to the requirement to pass a 'Citizenship Test', there appears an inherent understanding of community cohesion that closely echoes the common (lay) understanding of 'integration' as a process in which minorities adopt majority values and practices: a one-way process. And this narrow understanding of cohesion was evident in countryside organisations' approaches to positive action initiatives. Events targeting visible communities aimed to 'bring them' into the countryside, to 'introduce them' to 'our' wildlife, 'our' traditions and 'our' values and practices, with the expectation that 'they' will adopt/conform to these traditions, values and practices. A key example is the construction of 'acceptable behaviour' in the rural. Alongside a Countryside Code outlining 'dos and don'ts' regarding wildlife and habitat conservation, the research found unwritten rules of behaviour that are culturally circulated. These include being quiet, undertaking passive activities, and maintaining a sense of 'decorum': 'being unobtrusive and respectful' and 'keeping standards up', with an (often implicit) understanding that large group visits, parties/celebrations, or playing (loud or indeed any) music, are not appropriate activities/behaviour in national parks.

Examined more closely, though, these dominant values are context- and identitydependent. Large group visits often take place, with coach loads of older retired people in particular welcomed at market towns and visitor centres. Open air concerts are acceptable - promoted! - when 'properly' organised and with specific, 'appropriate' musical genres. And scenic rural settings remain popular with wedding parties. However, visible community groups visiting the countryside with the Mosaic project turned heads that a similar size group of white ramblers wouldn't. And in one interview, a visitor centre member of staff talked about a situation where a 'large group of Asians' had been spotted by residents and visitors in the Peak District, who had contacted national park rangers concerned that these might be terrorists, and the park staff had actually deliberated whether to contact the police. Instead, a ranger went to talk to the group (actually a dozen strong), who, it transpired, were celebrating a religious occasion. Positive action within a community cohesion agenda does nothing to derail racism if it ignores/denies dominant social constructions of others, or fails to question whose cultural practices are legitimate by (re)acting hypocritically towards practices common across groups.

Insert Figure 2: How different, how similar? 
So, neither cultural pluralism nor community cohesion address the need to combat continuing essentialism and ethnic stereotyping in rural areas. So, while the research clearly showed that positive action is an important catalyst to including visible communities in the countryside, and that cultural sensitivity is critical to social equality, it also suggested a need for a new approach incorporating both the positive aspects of cultural relativity alongside a recognition/acceptance of universal behaviours. Crucially, people are at the same time:

"both natural and cultural beings, sharing a common human identity but in a culturally mediated manner. They are similar and different, their similarities and difference do not passively coexist but interpenetrate, and neither is ontologically prior or morally more important."

(Parekh, 2000a:239, emphasis added)

This emphasis on difference and similarity as interconnecting requires a fundamental shift in outlook. To enable progressive positive action, visible communities (and white ethnic groups), cannot be automatically construed as 'having' fixed cultural values based on their (visible) ethnic background - while at the same time being open to cultural specificity. At this point, then, I want to consider a more provocative engagement with otherness that complicates binaristic or reductive tendencies.

monsters not strangers: visible communities and the English countryside

I have drawn elsewhere on Sara Ahmed's conceptualisation of 'the stranger' to unpack the ways in which the non-white body is constructed as other or threat in the English countryside (Askins, 2006). I want to work through and beyond such always already othering here to explore the potential for a more transformative politics of encounter. Ahmed (2000) writes that 'the stranger' is recognised not as someone unknown to us, but constructed already as different. Productions of 'the stranger', then, are tied up with the history of previous meetings and experiences between 'us' and 'them' attached to this recognition - and with socialised understandings of previous encounters between 'our' group and that of 'the stranger'. Significantly, stranger stereotypes incorporate ideas of potential threat, and this works both ways: 'they' fear 'us' as 'we' fear 'them' - thus, visible communities' anxiety about their reception in a dominant white countryside mirrors and is reflected by white fears around their presence. But it is through unequal power structures and notions of territorial ownership that these constructions lead to social exclusion based on visible difference. To accept the figure of the stranger as simply present conceals the 
antagonistic social relations that produce the stranger as a figure in the first place, and the materiality of these relations. As such, Ahmed questions the ontological possibility of strangers in the sense of the 'unknown', because strangers are presumed known, and argues that such productions of difference should be theorised through:

"thinking about the role of everyday encounters in the forming of social space ... Such differences are not then to be found on the bodies of others, but are determined through encounters between others; they are impossible to grasp in the present."

(Ahmed 2000:9, orig. emphasis)

But if this is the case, then how do shifts in perceptions of the other ever occur? At some point, in some present, change can happen - I believe the research evidenced such change, but catching hold of it and describing it has been and remains a tricky task!

I want to suggest that the concept of 'monsters' and 'the monstrous' may offer a way towards grasping shifts in the production of the other, drawing on the work of Sue Ruddick (2004). She writes that the idea of monsters is useful because, unlike strangers, the monstrous directly engages with issues of recognised difference, and as such enables a more honest, open connection with how we act towards/act upon our others. Monsters have been imagined and produced in response to anxiety about difference across human societies and throughout histories: the monster is different from 'us' and we acknowledge 'it' already as such. Moreover, the concept allows us to - demands that we - capture the ambivalence accorded difference: monsters are held in fear but also in awe. What makes working with this ambivalence valuable in the context of (re)viewing rural others is that it forces us to engage with difference that simultaneously evokes awe/interest even as it threatens, and it is this which facilitates the potential for a radical openness - an alternative engagement with an other (see also Haraway's (1992) 'promise of monsters').

Ruddick, drawing on Derrida, explains that the fear response leads not only to revulsion and exclusion, but also to an attempt by majority society to 'domesticate' the monster, to get 'it' to assume the habits of dominant society. This resonates with community cohesion discourses, and the ways in which countryside organisations attempt to introduce visible communities to the English countryside, via the 'correct' cultural practices and values. The awe response, on the other hand, leads to a 
celebration of ethnic difference - the positive pluralism of African Caribbean carnivals, Asian Melas, etc. Ruddick's project goes further than exam ining fetishism, though, invoking the radical openness of "that uncomfortable and disquieting moment" to suggest that monsters themselves are capable of 'domesticating' majority society - the popularity of chicken tikka masala or the impact of 'black' music on the mainstream are two often cited examples of shifts in English culture that perhaps illuminate this point. What is so important about conceptualising this reverse influence is that it allows for and highlights an agency and subjectivity of the monster that is denied the stranger. And this is important because the research clearly showed that visible communities not only resist being positioned as 'outsiders' in the English countryside, but claim the countryside and country as multicultural and multiethnic (Askins, 2006). Thinking about visible communities provocatively as monsters in the rural entails effacing the fear caught up in dominant constructions - the threat to 'traditional white' English identity occurs in the fact of multi-ethnic England, hence the anxiety around the presence of this new/different Englishness in the nation's perceived 'traditional white' space - and, crucially, how this is bound up in material exclusions ... while at the same time acknowledging the awe of the other, and how both aspects play with and against each other. The transformative potential of the concept lies in the possibility that visible communities may domesticate dominant society - in any/all of its spaces.

However, monsters as feared and fetishised are still and only caught up with difference, and thus fall short of Parekh's contention that people's similarity and difference interpenetrate. What I believe the monstrous offers is the technique of thinking radically, a strategy to think inclusively beyond notions of a singular way of being, or singular reactions to an other being. This alternative engagement:

"requires that we be able to hold onto that uncomfortable and disquieting moment before we collapse the other into someone 'just like us' (the pitfalls of certain forms of class and gender politics) or damn them into an irreconcilable 'them'. It begs the question: 'how are we to handle what is other without robbing it of its otherness?"”

(Mason, 1990; cited in Ruddick, 2004:26)

Insert Figure 3: "how are we to handle what is other without robbing it of its otherness?"

A strategy of radical openness - retaining that disquieting/uncomfortable moment of unknowingness where and when difference and similarity are ambiguous - enables 
an engagement with the im/possibility of the other, a way to grapple with the interconnectivity of difference and similarity. Mindful of Ahmed's writing about ontology and strangers, I do, however, think that new, transformative engagements may potentially occur in the moment of encounter ... or/and in the moments that follow. That is, during situations where/when we encounter otherness we may find our stereotypes challenged and shift our perceptions accordingly; or this can occur on reflection, after such encounters. The role of encounter may be important, the openness is critical.

I'm arguing, then, that the positive action and targeted outreach programs suggested through the research need to emanate from an ideology based on radical openness. What might such thinking look like in terms of policy, though? At the very least, positive action must be open to the range of possibilities of ethnic difference: celebrating cultural difference must be accompanied by also accepting other values and traditions regarding countryside practices - if you have henna tattooing at the countryside fair then you should also appreciate different cultural behaviours, perhaps large groups or picnics with music, in rural areas. More progressively, national parks need to hold the interconnectivities between difference and sameness at the core of positive action - targeting visible communities within programmes that also reach out to other groups identified as largely excluded from the countryside, working with visible communities separately where that need is identified, but also basing positive action on cross-cultural themes that enable people to come together. A key example identified in the research was a 'healthy living' focus - walking and food growing and cooking initiatives. Such progressive action is vital if national parks are to grasp the reality of a multiethnic England and move beyond fear. And critical within this project of rethinking identities is rethinking the spaces in which they play out.

\section{(re)placing the countryside: engagement across rural-urban Englishness}

\section{towards an emancipatory countryside}

There is an ever-developing and rich literature around multi-ethnicity, social inclusion, hybrid identities and transformative intercultural interaction in Britain (and more widely). Multi-ethnic encounters in places of work, school, consumption, leisure 'spaces of everydayness' - are discussed as sites where people contest fixed

identities, traverse cultures and negotiate difference, with the very local, the 
'micropublic', imperative in reconciling ethnic and cultural differences (Back, 2002; Houston et al., 2005). These are spaces where 'prosaic negotiations' are mandatory, and as such enable often imperceptible yet on-going cultural investigations and transruptions (Hesse, 2000; Amin, 2002). They are spaces of 'emergence', with the potential for cultural displacement and shift, where identities, values and practices can meet, dis/agree, merge and disentangle in such processes of negotiation. If we consider these sites closely, however, we are returned to the everyday urban as equated with such daily arbitration in encounters with ethnic difference. Cities as the spaces of inter-cultural and inter-ethnic potential, where monsters may be domesticated and may domesticate majority society. A new Englishness may be struggling into existence, but it appears to be restricted to a 'cosmopolitan urbanity' and isolated from a 'rural idyll', enabling the latter to retain its hegemonic whiteness that fears the visible community other.

In the research, however, while space was essentialised (with dualistic constructions of rural versus urban), it was also perceived as porous, mobile and plural. Senses of belonging in the English countryside were constructed by visible communities in complicated and contested ways that drew upon other ruralities across the world through diasporic and cultural memories, and people recognised themselves as English in multiple, hybrid and fluid ways that positioned the countryside within a web of national spaces (Askins, 2006). Space as both different and similar appeared interdependent within people's everyday geopolitics around fear and belonging indeed, the impact of a range of spatialities on identity and social relations is difficult to over-estimate, in particular the more subtle shades to identity that are influenced by movement (physical and emotional) across, through and between many spaces (eg. see Lewis \& Neal, 2005; Yuval-Davis et al., 2005). These multiple identifications demand that the rural engages with notions of multi-ethnic citizenship and claims to nationality: that the rural sees itself and is seen as a multicultural space. And this in turn will entail de-privileging the urban as the only site of multi-ethnicity and multiculturalism in England.

Now, I can't suggest that the countryside be considered as everyday space for people from Asian and African Caribbean backgrounds living in England (or for the majority of English society, for that matter). But I think there is a need to re-envisage national parks and the rural more widely as potential sites of prosaic inter-ethnic and inter-cultural negotiation, as spaces of emergence, where visible communities can be and are present. Importantly, the countryside can no longer be viewed as a place that 
'accommodates' or 'welcomes' other (than white) ethnic groups, which substantiates a fantasy of white supremacy that, even at its most 'benign', patronisingly speaks of 'tolerance' and 'welcome' while mistakenly believing that such tolerance or welcome is majority white society's to give (see Hage, 1998). Instead, there is a need to decentre the position held by Anglo-Saxon history in national park narratives rurality must be re-placed in the national imaginary as a space that may compose and is composed of multiple, hybrid and shifting ethnic identifications. The obvious flip-side to this is that thinking about ethnicity, citizenship, multiculturalism and national identity must engage with the rural, in order to avoid the tendency to always already re-site multi-ethnicity only in the city. Reconstructing the rural as mobile or incorporating mobility, as a space of multi-ethnicity, will require being open to plural values and claims to national identity and belonging. A 'politics of propinquity and flow' (Amin \& Thrift, 2002) need to be brought to bear in the rural as much as in the urban - or, rather, across these spaces. We need, then, in theory, policy and practice, a serious commitment to the relativity of space (Massey, 2004).

Insert Figure 4: National parks as sites of negotiation

So, I am arguing for a transformative geopolitics that not only attempts to juggle with simultaneous difference and similarity within identities, but also encapsulates the ways in which space as different and similar is interwoven through identity production. In the policy recommendations arising from the research, I suggest that positive action needs to focus on two main factors: facilitating encounters to unpack difference/similarity between and across groups (as mentioned in the previous section); and mediating such meetings across rural/urban space. Importantly, and mostly lacking in initiatives aiming to increase visible communities' access to the countryside, encounters need to be two-way exchanges. Work needs to be done across the rural/urban divide commonly invoked in social imaginaries, to highlight links and explore differences in terms of perceptions of place. The onus shouldn't always be on urban visible communities to visit the countryside: rural white communities, and countryside managers especially, should experience an encounter in the city if cultural exchange rather than voyeurism is to occur, meeting visible communities in the neighbourhoods where they live or places where they work, rather than only meeting them in the national park and 'showing them' around.

And let me finish on an encouraging note. While the Mosaic project focused on enabling trips to the countryside, much was learned through its experiences and, 
about the time I finished my research, the CNP were successful in securing a further three years funding to take the initiative forward. Renamed the Mosaic Partnership to reflect changes in emphasis, it aims to "broaden the range of people involved in caring for and influencing the future of National Parks"3. It encourages and supports 'community champions' from within visible communities to act as links between national parks/countryside managers and urban residents, as well as working with the national parks to effect meaningful organisational change. And the Community Champions Annual Event 2007, where national park staff and visible communities come together, took place in the city of Bradford ... with trips out to nearby countryside, of course.

\section{Acknowledgements}

To all involved with Mosaic, and everyone who participated in the research (funded through ESRC CASE studentship award no. S42200034003, with the North York Moors national park as CASE partners) - for so many (almost imperceptible!) moments of transformative encounter ... To Rachel for encouraging me to write against my stubborn instinct!

\section{References}

Agyeman, J. \& Neal, S. (eds.) (2006) The New Countryside?: Ethnicity, Nation and Exclusion in Contemporary Rural Britain, London: Policy Press.

Ahmed, S. (2000) Strange Encounters: Embodied Others in Post-Coloniality. London: Routledge.

Alibhai-Brown, Y. (2001) Mixed Feelings: the Complex Lives of Mixed-Race Britons, London: The Women's Press.

Amin, A. (2002) 'Ethnicity and the Multicultural City: living with diversity', Environment and Planning A 34, pp. 959-980.

Amin, A. \& Thrift, N. (2002) Cities: Reimagining the Urban, London: Polity Press.

Askins, K. (2006) 'New countryside? New country: visible communities in the English national parks', in J. Agyeman and S. Neal (eds) The new countryside?: Ethnicity, nation and exclusion in contemporary rural Britain, pp. 149-172. London: The Policy Press.

\footnotetext{
${ }^{3}$ See: www.mosaicpartnership.org
} 
Back, L. (2002) 'Guess who's coming to dinner? The political morality of investigating whiteness in the gray zone', in V. Ware \& L. Back Out of Whiteness: color, politics and culture, London: University of Chicago Press, pp. 33-59.

BEN (2003) Ethnic Environmental Participation (vol. 4), Llanberis: BEN Sharing Good Practice Series.

Bennett, D. (ed.) (1998) Multicultural States: Rethinking Difference and Identity, London: Routledge.

Bhattacharyya, G. (1998) 'Riding Multiculturalism' in D. Bennett (ed.) Multicultural States: Rethinking Difference and Identity, London: Routledge, pp. 252-266.

Bunting, M. (2007) 'United stand' The Guardian, June $13^{\text {th }}$.

Cantle, T. (2001) Community Cohesion. A Report of the Independent Review Team, (The Cantle Report), London: Home Office.

Cloke, P. \& Little, J. (1997) Contested Countryside Cultures, London: Routledge.

Fraser, N. (1995) 'From redistribution to Recognition? Dilemmas of Justice in a "PostSocialist" Age', New Left Review 212, pp. 68-93.

Hall, S. (2000) 'Conclusion: the Multi-cultural Question' in B. Hesse (ed.) Un/settled Multiculturalisms: Diasporas, Entanglements, Transruptions, London: Zed Books, pp. 209-240.

Hage, G. (1998) White Nation, Annandale, NSW: Pluto Press.

Haraway, D. J. (1992) 'The promise of monsters: a regenerative politics for inappropriate/d Others', in L. Grossberg, C. Nelson \& B. Treichler (eds.) Cultural Studies, New York: Routledge, pp. 295-337.

Hesse, B. (ed.) (2000) Un/settled Multiculturalisms: Diasporas, Entanglements, Transruptions, London: Zed Books.

Houston, S., Wright, R., Ellis, M., Holloway, S. \& Hudson, M. (2005) 'Places of possibility: where mixed-race partners meet', Progress in Human Geography, 29(6) pp. 700-717.

Lewis, G. \& Neal, S. (2005) 'Introduction: Contemporary political contexts, changing terrains and revisited discourses', Journal of Ethnic and Racial Studies 28(3) pp. 423444.

Massey, D. (2004) 'Geographies of responsibility', Geografiska Annaler 86 B (1), pp. 5-18.

Milbourne, P. (ed.) (1997) Revealing Rural Others: Representation, Power and Identity in the British Countryside, London: Pinter.

Modood, T. (1992) Not Easy Being British: Colour, Culture and Citizenship, Stoke-onTrent: Runnymede Trust and Trentham Books. 
Neal, S. (2002) 'Rural landscapes, representations and racism: examining multicultural citizenship and policy-making in the English countryside', Ethnic and Racial Studies, 25(3), pp. 442-461.

Parekh, B. (2000a) Rethinking Multiculturalism: Cultural Diversity and Political Theory, London, Palgrave.

Parekh, B (2000b) The Future of Multi-Ethnic Britain, London: Profile Books.

Rattansi, A. (1999) 'Changing the subject? Racism, culture and education', in J. Donald \& A. Rattensi (eds.) 'Race', Culture and Difference, London: Sage, pp. 11-48.

Ruddick, S. (2004) 'Domesticating Monsters: Cartographies of Difference and the Emancipatory City', in L. Lees (ed.) The Emancipatory City. Paradoxes and Possibilities, London: Sage, pp. 23-39.

Wells, K. \& Watson, S. (2005) 'A Politics of Resentment: Shopkeepers in a London Neighbourhood', Journal of Ethnic and Racial Studies 28(2) pp. 261-277.

Williams, P. (1997) Seeing a Colour-Blind Future: the paradox of race, London: Virago.

Yuval-Davis, N., Anthias, F. \& Kofman, E. (2005) 'Secure borders and safe haven and the gendered politics of belonging: Beyond social cohesion', Journal of Ethnic and Racial Studies 28(3) pp. 513-535. 